LUBLIN STUDIES IN MODERN LANGUAGES AND

LITERATURE 40(1), 2016, HTTP://WWW.LSMLL.UMCS.LUBLIN.PL, HTTP://LSMLL.JOURNALS.UMCS.PL

Ferit Kılıçkaya

Mehmet Akif Ersoy University

İstiklal Campus, 15100 Burdur, Turkey

\title{
Washback effects of a high-stakes exam on lower secondary school English teachers' practices in the classroom
}

\begin{abstract}
The aim of the article is to investigate the effects of the foreign language section of TEOG (Transition Examination from Primary to Secondary Education) on language teacher practices in the classroom. The participants of the study include 30 English language teachers working at lower secondary schools in Turkey. The results of the study indicate that language teacher practices in the classroom are greatly affected by several factors such as the style and content of the language exam. The main harmful washback of this exam is found to be the neglect of teaching several skills such as listening, speaking, and writing as these skills are not assessed, and stakeholders such as students and parents require reasonable level of success on these texts. Some other factors negatively affected have been found to be the selection of course books, the medium of instruction, classroom assessment as well as anxiety.

Keywords: washback, English language teachers, exam, tests, lower secondary schools
\end{abstract}

1. Introduction

Assessment proves to be crucial and plays an important role in any educational context. Assessment may appear in various forms, from 
multiple-choice tests and short-answer questions to classroom observation and portfolios (Chapelle \& Brindley, 2010; Brown \& Abeywickrama, 2010). No matter in what forms assessment may appear, it has several benefits to all the stakeholders given that reliable and valid assessment is conducted. While the results of assessment inform both teachers and learners of whether learners have achieved the learning outcomes and help teachers determine the weaknesses and strengths of learners, they prove useful to other stakeholders such as parents and policymakers to be informed on school and systemlevel performances.

Any assessment made, be it formative or summative, or teacher made or nation-wide, has an effect on both learners and teachers. Tests are expected to yield positive effects on teaching and learning in as well as outside the classroom. The classroom exams given by the teachers supply the instructors with information that help them determine the strengths and weaknesses of the students and act accordingly through doing necessary revisions, and, if required, make necessary instructional improvements. However, the results of the high-stakes tests have important consequences as the scores obtained on these tests often determine which students can pursue education at universities. Due to the pressure and consequences attached to the high-stakes tests, several effects can be observed. In literature, the term washback or backwash is used to refer the effects of testing. As Hughes (2003, p.1) states,

[t]he effect of testing on teaching and learning is known as backwash, and can be harmful or beneficial. If a test is regarded as important, if the stakes are high, preparation for it can come to dominate all teaching and learning activities.

Considering the student perspective, it may affect what they learn, how they get prepared for assessment as well as study habits. On the other hand, especially nation-wide examinations might lead to changes in teachers' instructional and assessment practices.

The impact of the examinations can be observed in the classrooms, publishing industry as well as the society. "The impact of test use operates at two levels: a micro level, in terms of individuals who are 
affected by the particular test use, and a macro level, in terms of the educational system or society" (Bachman \& Palmer, 1996, pp. 29-30). The impact of tests often results from content, skills, and format. Many tests aim to test grammar, reading, and vocabulary items, often using gap fill and multiple choices, which puts practicality foremost. These tests do not focus on the ability to communicate and neglect listening and speaking skills. Furthermore, most tests try to test grammar and vocabulary at the word or sentence level, ignoring the discourse level.

\section{Literature review}

There are several studies that investigated the effects of high-stakes tests on student and teacher practices. For example, Ferman (2004) investigated the effect of the English Foreign Language (EFL) Oral Matriculation Test on teaching and learning practices in the Israeli education system. The participants of the study included teachers, and EFL students, and the data were collected through questionnaires and interviews. The results indicated that the test changed the activities in the classroom, leading to more time allocated to practice on the oral skill. However, teachers stated that they would not deal with oral activities after the exam was over to focus on the written examination.

In a similar study, Qi (2004) investigated the effects of the National Matriculation English Test (NMET) in China on language teachers' instructional practices in the classroom. The interviews conducted with teachers indicated that classroom activities focused on the skills of listening, reading, and writing as intended by the test constructors although the format used in teaching and learning activities included multiple-choice items to test comprehension. Including a listening section in the test was highly valued by the teachers.

On the other hand, Choi (2008), in the review of the impact of EFL testing on foreign language learning and teaching in Korea, states that EFL tests are not valued by test-takers and teachers as they believe that testing leads to negative washback effects. The main negative effect is found to be the mismatch between the content and the format 
(multiple-choice questions) of the examinations and English proficiency, leading to the neglect of productive English skills.

Amengual-Pizarro (2009) analyzed the effect of the English Test included in the Spanish University Entrance Examination. The results indicated that the teachers focus on the materials as well as the skills that match the purpose of the English Test. In other words, the teachers teach to the test and neglect the practice of skills such as speaking, which indicates that the English Test has the effect of narrowing the curriculum to the tested skills and materials.

In another study, Turner (2009) examined the effects of a highstakes provincial English exam on teacher practices in the language classrooms in Quebec secondary schools. The results indicated that although there were variations in teachers' individual practices, teachers intentionally focused on practicing speaking skill through tasks and activities similar to the ones tested in the exams and provided students with the opportunity to practice speaking.

Pan and Newfields (2011) analyzed the effects of English certification exit examination on teachers and students. Based on the self-reports obtained, the results indicate that teachers devote little amount of preparation for the test, do not change their practices in the classroom and are willing to focus on basic language skills although students express the need for explicit instruction and activities that focus on the exam.

Sukyadi and Mardiani (2011) analyzed the impact of the English National Examination, a school leaving examination, on language classroom practices taking both teachers and students into consideration. The results suggest that teachers mainly teach to the test and focus on test-taking strategies while students practice vocabulary, listening, and reading.

In another study, Zhan and Andrews (2014) investigated the washback effects of CET-4 on Chinese non-English major undergraduates within the context of tertiary education in Mainland China. The study focused on the impact of CET-4 on students' out-ofclass learning practices. The results suggest that the learners attached more importance to the practice of listening and readings skills as 
these skills are tested on the exam. Learner practices include review of past examinations and other mock exams. The most striking result of the study is that learners seem to have changed what they learn rather than how they learn, indicating that their out-of-class learning practices are oriented towards memorization rather than communication.

The studies conducted within the Turkish contexts where English is taught as a foreign language included high school students, university graduates, and academics as participants while investigating the effects of several high-stakes language examinations. For example, Sevimli (2007) investigated the effect of the Foreign Language Exam (FLE) section of the university entrance exam on teaching and learning in the secondary schools. The findings revealed that FLE affects teaching and learning negatively as the activities done and materials used in the language classrooms are completely based on what is tested on FLE. It was found that classroom time is allocated to procedures such as test-taking strategies and practices on grammar, vocabulary, and reading activities, neglecting skills such as listening and the productive skills, which are speaking and writing.

In a similar study, Karabulut (2007) analyzed the effect of the foreign language section of the university entrance exam on how teachers teach and students learn in the last grade of high school in Turkey. The data were collected through online surveys. The test was found to be the major factor that affects how English lessons are conducted. The findings also indicated that the students' main aim of language learning is limited to scoring high on the test through practicing grammar, reading, and vocabulary. Likewise, teachers were found to practice these areas to help students score better on the tests although they acknowledge the need for productive skills such as writing and speaking to improve the ability to use the language.

Yildirim (2010), on the other hand, focused on the effects of the English section of the university entrance exam on the future language teachers (YDS, Foreign Language Exam), which is used for admission to language, literature and language teacher training departments in Turkey. The study specifically analyzed the students' language 
proficiency and their academic performance in their departments. The results revealed the negative effects on students' language performance and proficiency as the students spent a great deal of exam preparation time answering mock exam questions, learning about test-taking strategies, and focusing on the knowledge tested on the exam. The main reason for their poor performance in the department is found to be the practice during the exam preparation on reading, grammar and vocabulary, ignoring the skills needed for communication and academic contexts such as speaking, listening, and writing.

In another study, Özmen (2011) aimed to determine the washback effect of ÜDS (Inter-university Foreign Language Examination) on the test-takers. The participants of the study included twelve academicians working at different universities. The results of the study indicated that the participants were affected negatively due to the content of ÜDS since it mainly aimed to test test-takers' knowledge of grammar and vocabulary in addition to the reading skill. They reported that they could not study and/or improve other skills such as speaking as these skills were not tested.

In a similar study, Akpınar and Çakıldere (2013) analyzed the washback effects of two high-stakes examinations in Turkey: KPDS (State Personnel Language Examination) and ÜDS (Inter-university Foreign Language Examination). They adopted a survey research design to analyze the effects of these two examinations on Turkish academicians' receptive and productive skills. They found that KPDS and ÜDS have strong positive washback effect on reading skills but strong negative effects on listening, speaking, and writing as these skills (listening, speaking, and writing) are not tested on the examinations.

Similarly to the previous study, Dağtan (2012) analyzed the washback effect of ÜDS (Inter-university Board Foreign Language Test). The participants included the faculty members of Dicle University located in Diyarbakır in Turkey. Based on the responses provided by the participants to the questionnaire and the interviews help, the findings indicated that ÜDS has a positive effect on reading 
skill as it tests reading skill. However, ÜDS is found to have negative effect on listening, speaking, and writing as these skills are not practiced and ignored by the test-takers.

Finally, Şentürk (2013) analyzed the effect of KET (Key English Test) on classroom interactions and practices in a private college. The results indicate that the teacher changes the way she teaches English in the classroom, taking the language skills included in KET. Since KET is based on the communicative abilities in English, it has been observed that the teacher also includes receptive and productive skills in the classroom activities, which is considered as a positive effect of washback.

\section{Study}

\subsection{Purpose of the research}

Although there are various studies investigating the effect of nationwide high-stakes language examinations on learners at various levels of education such as upper secondary education, to the best knowledge of the researcher, there is no study conducted on the foreign language examination included in Transition Examination from Primary to Secondary Education (henceforth referred to as TEOG). Furthermore, most studies conducted in Turkey have addressed the effect of high-stakes testing within the perspective of students; there is little exploration of teachers' opinions and experiences.

Therefore, the current study aims to probe the washback effects of the foreign language examination section of TEOG on language teacher practices. The research question of the study is stated as follows: What are the harmful and beneficial effects of the language section included in TEOG on teaching practices of language teachers of 8 th grade? 
3.2. Background information on TEOG (Transition Examination from Primary to Secondary Education)

English is taught as a foreign language in the Turkish context, and it is the only required foreign language taught to students at all levels (Kırkgöz, 2007). Compulsory education in Turkey lasts 12 years, including primary, lower and upper secondary education of 4 years each. At the end of grade 8, students are required to take TEOG in order to seek admission to upper secondary education (high schools). TEOG is a high-stakes test prepared by the Ministry of National Education (henceforth MoNE). The results are used to select students at age around 14 into upper secondary schools, which is generally regarded vital by both students and parents as high scores on this test will help students be admitted to 'highly successful' upper secondary schools where admission to tertiary education is almost guaranteed. Based on a multiple-choice format which is mainly used to obtain 'reliability' and 'practicality' in scoring (Bachman \& Palmer, 1996), TEOG is taken by $8^{\text {th }}$ graders twice a year: during the first semester, generally in November, and during the second semester, generally in April. It includes several subjects based on the curriculum of lower secondary school, one of which is a foreign language, which might be German, French, English, or Italian depending on students' preference. Contrary to the expected practice of both receptive and productive skills in the classroom (MoNE, 2006, p. 203), the foreign language section (English) of TEOG includes 20 multiple-choice questions that test students' knowledge of grammar and vocabulary, and reading, totally neglecting listening, writing, and speaking skills (MoNE 2015). There is not any information provided by the testconstructors on test specifications although test takers should know why they will be assessed, what will be tested on the exam and what the results will mean.

\subsection{Research context and participants}

The research context for the study were lower secondary public schools in central Burdur, Turkey. Of all the lower secondary schools, 15 schools were randomly selected. Then, the teachers who teach the 
$8^{\text {th }}$ graders were determined. There were 32 teachers teaching $8^{\text {th }}$ graders. These 32 teachers were informed about the aim of the study and asked whether they would like to participate in the study. Except 2 teachers, 30 teachers gave their informed consent to participate in the study. The teachers were aged between 28-45 and their experiences of teaching English varied from 6 to 20, with the average of 12.4 years. 5 of the teachers were male, while the rest were female. They were all graduates of English language teaching departments, and two of the teachers hold Master's degree in English language teaching.

3.4. Data collection and procedure

A qualitative approach to data collection was adopted to seek answers to the research questions as the responses would be based on personal experience and reflection. The data were collected through semistructured interviews conducted with the participants. Towards the end of the spring semester in 2015, the participants giving consent to participate in the study were contacted, and based on their schedule, an interview day was determined. The interviews were conducted in Turkish with one participant at a time either in the teachers' room or in a class depending on the availability of the places to explore their in-depth thoughts underlying their teaching as well as assessment practices. The interviews lasted 25 or 35 minutes and were recorded using a digital recorder and transcribed verbatim except two interviews as the participants did not agree. In this case, the researcher tried to take notes in detail of the responses provided by the participants.

The following questions were asked during the interviews:

(1) Which language skills do you focus on your language classrooms?

(2) What kind of assessment practices do you employ in your classrooms?

(3) Are there any kinds of assessment practices that you would like to apply but cannot? What are the reasons? 
(4) Does the foreign language section included in TEOG affect how you teach and which materials you choose? In what ways?

(5) Do you have any other comments / suggestions?

\subsection{Data analysis}

The data collected through semi-structured interviews and the exam papers were subject to content analysis. The data analysis was initially done by the researcher. The responses to the interview questions were coded for themes and patterns. Unnecessary breaks and pauses in the responses were omitted. After the initial data analysis, the wordprocessed transcripts were shared with another experienced researcher with a Ph.D. in English language teaching. In order to ensure the credibility of the themes and patterns, regular meetings were held with this researcher to discuss the common codes, to compare codes and patterns, and to make necessary changes. In order to ensure consistency between the coders and the reliability of the content analysis, Kendall's Coefficient of Concordance Law was calculated. The coefficient of concordance was found to be .853 for the codes and patterns that emerged in the responses provided to the interview.

\section{Findings and discussion}

The themes and the codes in addition to the example responses emerging from the interviews have been provided in Table 1. The selected quotations included are the most representative of the findings of the study.

Table 1. Coding Scheme

\begin{tabular}{lll}
\hline Themes & Codes & Examples \\
\hline $\begin{array}{l}\text { Language } \\
\text { areas / skills }\end{array}$ & $\begin{array}{l}\text { Grammar } \\
\text { Reading } \\
\text { (comprehension) } \\
\text { Vocabulary }\end{array}$ & $\begin{array}{l}\text { "I just focus on improving my students' } \\
\text { reading skills and vocabulary } \\
\text { knowledge as these is what is tested on }\end{array}$ \\
\end{tabular}




\begin{tabular}{|c|c|c|}
\hline $\begin{array}{l}\text { Teaching } \\
\text { materials }\end{array}$ & $\begin{array}{l}\text { Main coursebook } \\
\text { Supplementary } \\
\text { coursebook(s) } \\
\text { Supplementary exercises } \\
\text { / materials }\end{array}$ & $\begin{array}{l}\text { "I use the content of the main } \\
\text { coursebook to create vocabulary lists } \\
\text { and to determine grammar structures. } \\
\text { As the main course is selected by } \\
\text { Ministry of Education and it is not } \\
\text { sufficient to prepare for the exam, we } \\
\text { use materials from other coursebooks } \\
\text { in addition to the exercises I prepare." }\end{array}$ \\
\hline $\begin{array}{l}\text { Teaching } \\
\text { style }\end{array}$ & $\begin{array}{l}\text { Lecturing } \\
\text { Blend of Grammar } \\
\text { Translation / Reading / } \\
\text { Lexical Approaches }\end{array}$ & $\begin{array}{l}\text { "I teach grammar structures and } \\
\text { vocabulary. We translate the dialogues } \\
\text { into Turkish and my students memorize } \\
\text { list of words in English with Turkish } \\
\text { equivalents." }\end{array}$ \\
\hline $\begin{array}{l}\text { Assessment } \\
\text { formats }\end{array}$ & $\begin{array}{l}\text { Formative } \\
\text { Summative } \\
\text { Multiple choice } \\
\text { Matching } \\
\text { Gap filling } \\
\text { Observing student } \\
\text { performance }\end{array}$ & $\begin{array}{l}\text { "My exams include questions that } \\
\text { match the format of the exam. From } \\
\text { time to time, I give them quizzes to } \\
\text { assess their performance through } \\
\text { multiple choice and matching activities. } \\
\text { But at the end of the semester, when I } \\
\text { give their final grade, I also consider } \\
\text { students' participation in the class, } \\
\text { whether they did their homework } \\
\text { throughout the semester." }\end{array}$ \\
\hline $\begin{array}{l}\text { Medium of } \\
\text { instruction }\end{array}$ & $\begin{array}{l}\text { Turkish (most) } \\
\text { English (least) }\end{array}$ & $\begin{array}{l}\text { "I often use Turkish to explain the } \\
\text { grammar structures and the meanings } \\
\text { of the words due to limited classroom } \\
\text { hours. }\end{array}$ \\
\hline Anxiety & $\begin{array}{l}\text { Teachers } \\
\text { Students forced to be } \\
\text { successful }\end{array}$ & $\begin{array}{l}\text { "Not just my students suffer from } \\
\text { anxiety. I also feel anxious. I feel that if } \\
\text { my students fail the test, I will also fail } \\
\text { as their teacher. We have to be } \\
\text { successful." }\end{array}$ \\
\hline
\end{tabular}

\subsection{Language areas/skills}

The responses provided clearly indicate that the participants focus only on grammar, vocabulary, and reading in classroom activities. Almost all of the participants $(n=28)$ stated that they tried to improve 
students' knowledge of grammar structures through explicit instruction, knowledge of vocabulary through word lists including example sentences, and reading skills through short dialogues and sentences similar to the ones tested on the exam by having students read as much as possible in and outside the classrooms. While two participants stated that they tried to engage students with listening and speaking activities, a little amount of classroom time was allocated to these activities, or most students were not willing to participate. All the participants were well-aware that students should learn how to communicate in the language they are learning and all the four skills should be included in the classroom activities to promote communication, they expressed that they were forced to teach to the test as getting high scores on the language section of TEOG were more important than anything else not only to the students but also to the parents. One of the participants expresses the focus of the classroom as follows:

I teach grammar structures deductively as four hours a week is not enough to cover all the topics included in the book. After some drill exercises on grammar, we review the vocabulary in the unit through the vocabulary lists I have prepared. My students have a vocabulary notebook on which they write the new words on the left and the meanings on the right columns of their notebooks. I also ask them to write some example sentences for these words (Interviewee 10, Male).

\subsection{Assessment formats}

The majority of the participants $(n=26)$ claimed that they both benefited from formative and summative assessment throughout the year. Formative assessment included announced quizzes given in the classroom, while the formal exams given at the end of the units or several units served as summative assessment. Moreover, as some participants indicated $(\mathrm{n}=10)$, some homework was assigned to students to review what was covered in the classrooms to assess their performances. The common test formats of these quizzes and homework were found to be multiple choice questions testing grammar, reading, and vocabulary, and gap filling exercises geared towards testing grammar and vocabulary. The summative assessment practices of the participants included the similar test formats although 
the content coverage was different as it was the end of the semester. Two participants used listening comprehension exercises through short-answer questions in their written examinations in the classroom. However, the majority of assessment focused on grammar, reading, and vocabulary, neglecting writing, listening, and speaking. Testing techniques were also found to favor multiple-choice questions and matching activities, leaving no room for other types of assessment such as portfolios and projects. During the interviews, all the participants indicated that they had several classes in their undergraduate / graduate education such as foreign language testing and evaluation and educational measurement and evaluation and learnt a variety of classroom-based assessment techniques such as portfolios, keeping diaries, and self-assessment. However, with some exceptions, the participants could not benefit from the training as they expressed that the test format limited the use of alternative assessments included in the course contents (Hatipoğlu, 2015). It is also noteworthy that the participants were required by the regulations to give three official examinations, the average of which would determine the final grade of the students. Most participants $(n=24)$ stated that while assigning the final grade, they also considered some other factors such as whether the students did their assignments on time and observing students' performance while doing the activities, and whether they showed any disruptive behavior. The rest of the participants $(n=6)$ expressed the view that they just took the averages of the three official examinations and then assign the final grade. The following statement brings out how assessment is conducted:

I often give quizzes and distribute worksheets after several classes on grammar, reading, and vocabulary so that I can determine my students' strengths and weaknesses. Then, if necessary I review the grammar structures as well as vocabulary (Interviewee 5, Female).

\subsection{Teaching style}

The language section included in TEOG, as the previous findings indicate, seems to have affected negatively all the classroom practices from teaching methods to assessment techniques. A great majority of the participants $(n=27)$ expressed the view that the language areas and 
skills were just limited to grammar, reading, and vocabulary. Saying that listening, writing, and speaking are not tested on the exam, they were 'forced' to neglect these skills. Therefore, as indicated by the participants, a teacher-centered atmosphere appeared in the classroom, where the teacher lectured and decided on the materials and activities to be used. The teaching and learning processes were found to be based on grammar translation and vocabulary enrichment through reading.

\subsection{Teaching materials}

The responses during the interviews also revealed that the participants had to use some other 'coursebooks' or 'test books' as supplementary to the classroom activities as they found the coursebooks used in the classroom insufficient in terms of content, explanation, and input. They also believed that students had to learn some test-taking strategies studying the questions that matched the exam format. They complained that MoNE decides on the coursebooks to be used and they almost have no voice over this selection, which is also expressed by the participants of the study conducted by Korkmazgil and Seferoğlu (2013). One of the participants clearly points out this issue by saying that

I use the content of the main coursebook to create vocabulary lists and to determine grammar structures. As the main course is selected by Ministry of Education and it is not sufficient to prepare for the exam, we use materials from other coursebooks in addition to the exercises I prepare (Interviewee 13, Female).

\subsection{Medium of instruction}

One of the great benefits of qualitative research conducted through interview is that the analysis of the responses may reveal issues that the participants raised. The analysis of the responses in the current study, therefore, was not limited to the issues determined in advance. Some participants $(n=15)$ raised the issue of the language used in the classroom. The medium of instruction issue really lends itself to what is going on in the classroom. As the majority of the participants dealt with explicit instruction of grammar structures and teaching the 
meanings of words taking the exam into consideration, the language often used in the classroom turned out to be Turkish.

\subsection{Anxiety}

Another emergent theme is anxiety. As the focus of the study was teachers, the interview questions prepared in advance did not include questions on anxiety as it was believed it is the students only that suffer from anxiety. However, the reverse turned out to be in the findings. The participants expressed that they also suffered from anxiety. As indicated by the participants, they felt that their students should be successful and score higher on the language section of TEOG, which otherwise would mean that they cannot teach well and be held responsible for the results achieved by the students. The following extracts are typical examples:

We do so many grammar, reading and vocabulary activities that we do not have time to practice other skills. Parents, not just students, also ask us to prepare them for the test. It is no use talking about the importance of speaking and listening in English (Interviewee 2, Female).

These findings are consistent with those of the studies previously conducted (Ferman, 2004; Qi, 2004; Sevimli, 2007; Karabulut, 2007; Amengual-Pizarro, 2009; Turner, 2009; Yıldırım, 2010; Şentürk, 2013; Sukyadi \& Mardiani, 2011; Zhan \& Andrews, 2014). The common finding is that although there are some exceptions that might be called teacher-specific variations (e.g. Pan \& Newfields, 2011), the great majority of the teachers tend to teach to the test (or teach what is tested), narrowing the curriculum to the skills to be tested. In other words, they consider the content (language areas and skills) and the format (multiple choice questions etc.) with respect to what is tested on the high-stakes examinations and act accordingly in the classroom. While this might be valued and considered beneficial washback in some cases such as introducing the oral ability in the test (e.g. Ferman, 2004), in some other cases, it might result in the neglect of several skills such as listening and writing (e.g. Sevimli, 2007; Karabulut, 
Washback effects of a high-stakes exam on lower secondary school 13

2007). This is often stated to be due to the reasonable expectation of success of several stakeholders such as students themselves as well as their parents.

5. Conclusion and implications for the future

The current study investigated the effects of the foreign language section of TEOG on language teacher practices. The results of the study indicate that language teacher practices in the classroom are greatly affected by the content as well as the format of the language exam. The main harmful washback of this exam is found to be the neglect of teaching several skills such as listening, speaking, and writing as these skills are not assessed and stakeholders such as students and parents require a reasonable level of success on these texts. Some other factors negatively affected by this test are the selection of course books, the medium of instruction, classroom assessment as well as anxiety.

As the study indicates, high-stakes exams have great consequences for all the stakeholders. Considering teaching and learning foreign languages in the Turkish context, it can be stated that the overreliance on tests can result in several aspects, with certain skills and achievements being excluded. Rather than introducing useful language and developing productive skills such as speaking that will encourage learners to communicate, classroom practices are dominated by the approach of teach what is tested, leading to teaching and learning the content covered by the exam as well as the techniques that might lead to higher scores but lower abilities in language use. It is wellacknowledged that exams are unavoidable not just only due to accountability and selection issues but also the monitor of students' progress.

When assessment is conducted appropriately and carefully, it can provide valuable information on the neglected aspects of learning and show teachers and students as well as other stakeholders where progress falls short of expectations and what to do to remedy this low performance. Therefore, it is believed that if today's world values communication in various languages, teaching and learning should be 
based on communicative abilities. Accordingly, the assessment of learners' abilities should be based on these abilities. It is therefore suggested that although it may not guarantee the positive changes in the classroom practices, it will be the first beneficial step to change the content and the skills covered in exams such as TEOG, whose effects are discussed in this study, so that it should include receptive as well as productive skills, which might lead to adoption and practice of these skills as several studies indicate.

It needs to be noted that the findings are based on the data collected from the responses provided by a limited number of participants. Therefore, the findings might not be generalized but can be transferable to other similar settings. Further research is needed on several aspects such as taking other stakeholders' views into consideration as well as triangulating the data from several resources such as observing teacher practices in the classrooms.

\section{References}

Akpınar, K. D., \& Çakıldere, B. (2013). Washback effects of high-stakes language tests of Turkey (KPDS and ÜDS) on productive and receptive skills of academic personnel. Journal of Language and Linguistic Studies, 9(2), 81-94. Retrieved from http://dergipark.ulakbim.gov.tr/jlls/article/download/5000084297/5000078394.

Amengual-Pizarro, M. (2009). Does the English test in the Spanish university entrance examination influence the teaching of English? English Studies, 90(5), 582-598. doi: 10.1080/00138380903181031

Bachman, L. F., \& Palmer, A. S. (1996). Language Testing in Practice. Oxford: Oxford University Press.

Brown, H. D., \& Abeywickrama, P. (2010). Language Assessment: Principles and Classroom Practices (2nd ed.). White Plains, NY: Pearson Education.

Chapelle, C. A, \& Brindley, G. (2010). Assessment. In N. Schmitt (Ed.), An Introduction to Applied Linguistics (2nd ed., pp. 247-267). Abingdon, Oxon: Hodder Education.

Choi, I.-C. (2008). The impact of EFL testing on EFL education in Korea. Language Testing, 25(1), 39-62. doi: 10.1177/0265532207083744

Dağtan, E. (2012). An Examination of the Washback Effect of the Interuniversity Board Foreign Language Test (The Example of Dicle University). (Master's thesis, Dicle University, Diyarbakır). Retrieved from http://acikerisim.dicle.edu.tr/xmlui/handle/11468/862?show=full. 
Ferman, I. (2004). The washback of an EFL national oral matriculation test to teaching and learning. In L. Cheng, Y. Watanabe, \& A. Curtis (Eds.), Washback in Language Testing: Research Contexts and Methods (pp. 191-210). Mahwah, NJ: Lawrence Erlbaum.

Hatipoğlu, Ç. (2015). English language testing and evaluation (ELTE) training in Turkey: Expectations and needs of pre-service English language teachers. ELT Research Journal, 4(2), 111-128. Retrieved from http://dergipark.ulakbim.gov.tr/eltrj/article/view/5000161661/pdf_18.

Hughes, A. (2003). Testing for language teachers (2nd ed.). Cambridge: Cambridge University Press.

Karabulut, A. (2007). Micro level impacts of foreign language test (university entrance examination) in Turkey: a washback study (Master's thesis, Iowa State University, Ames, Iowa). Retrieved from http://lib.dr.iastate.edu/rtd/14884/

Kırkgöz, Y. (2007). English language teaching in Turkey: Policy changes and their implementations. RELC Journal, 38(2), 216-228. doi: 10.1177/0033688207079696.

Korkmazgil, S., \& Seferoğlu, G. (2013). Exploring non-native English teachers' professional development practices. Boğaziçi University Journal of Education, 30(1), 1-10. Retrieved from http://dergipark.ulakbim.gov.tr/buje/article/view/5000140041.

MoNE. (2015). English Exam Questions for Grade 8 in the Second Semester. Retrieved from http://www.meb.gov.tr/sinavlar/dokumanlar/2015/soru/Teog2Donem/YabanciDil. zip.

MoNE. (2006). English Language Curriculum for Primary Education (Grades 4,5,6,7 and 8). Retrieved from http://ttkb.meb.gov.tr/program2.aspx?islem=2\&kno=31.

Özmen, K. S. (2011). Washback effects of the inter-university foreign language examination on foreign language competences of candidate academics. NovitasROYAL (Research on Youth and Language), 5(2), 215-228. Retrieved from http://www.novitasroyal.org/Vol_5_2/OzmenKS.pdf.

Pan, Y., \& Newfields, T. (2011). Teacher and student washback on test preparation evidenced from Taiwan's English certification exit requirements. International Journal of Pedagogies and Learning, 6(3), 260-272. doi:10.5172/ijpl.2011.6.3.260

Qi, L. (2004). Has a high-stakes test produced the intended changes? In L. Cheng, Y. Watanabe, \& A. Curtis (Eds.), Washback in Language Testing: Research Contexts and Methods (pp. 171-189). Mahwah, NJ: Lawrence Erlbaum.

Sevimli, S. E. (2007). The Washback Effects of Foreign Language Component of the University Entrance Examination on the Teaching and Learning Context of English Language Groups in Secondary Education: A Case Study (Master's 
thesis, Gaziantep University, Gaziantep). Retrieved from https://tez.yok.gov.tr/UlusalTezMerkezi/.

Sukyadi, D. \& R. Mardiani (2011). The washback effect of the English National Examination (ENE) on English teachers' classroom teaching and students' learning. Kata, 13(1), 96-111. Retrieved from http://kata.petra.ac.id/index.php/ing/article/view/18214/18090.

Şentürk, F. (2013). Washback Effect of KET Exam in Learning English as a Foreign Language (Master's thesis, Çağ University, Mersin). Retrieved from https://tez.yok.gov.tr/UlusalTezMerkezi/.

Turner, C. E. (2009). Examining washback in second language education contexts: A high stakes provincial exam and the teacher factor in classroom practice in Quebec secondary schools. International Journal of Pedagogies and Learning, 5(1), 103-123. doi: 10.5172/ijpl.5.1.103

Yıldırım, Ö. (2010). Washback effects of a high-stakes university entrance exam: Effects of the English section of the university entrance exam on future language teachers in Turkey. The Asian EFL Journal Quarterly, 12(2), 92-116. Retrieved from http://www.asian-efl-journal.com/PDF/June-2010.pdf.

Zhan, Y., \& Andrews, S. (2014). Washback effects from a high-stakes examination on out-of-class English learning: Insights from possible self theories. Assessment in Education: Principles, Policy \& Practice, 21(1), 71-89. doi: 10.1080/0969594X.2012.757546 